Explanation of Plates 30 and 31

Fig. 1. Idiocerus gemmisimulans, first stage nymph.

Fig. 2. Idiocerus gemmisimulans, second stage nymph.

Fig. 3. Idiocerus gemmisimulans, third stage nymph.

Fig. 4. Idiocerus gemmisimulans, fourth stage nymph.

Hig. 5. Idiocerus gemmisimulans, fifth stage nymph.

Fig. 6. Idiocerus gemmisimulans, adult male.

Fig. 7 . Idiocerus gemmisimulans, egg.

Fig. S. Idiocerus gemmisimulans, cluster of eggs in position.

Fig. 9. Idiocerus gemmisimulans, face of male.

Fig. 10. Idiocerus gemmisimulans, wing of male.

Fig. 11. Gonatocerus ovicenatus, male.

Fig. 12. Gonatocerus ovicenatus, female.

\title{
THE POISONOUS EFFECTS OF THE ROSE CHAFER UPON CHICKENS
}

By G. H. Lamson, JR., Storrs, Conn.

Serious losses have occurred each year during June and early July, from chickens having eaten the rose chafers (Macrodactylus subspinosus). These losses have often been ascribed to various causes but close observations have shown that the chickens are very fond of eating the insects and post mortem examinations have revealed the presence of many undigested rose chafers in their crops. The crops are usually so full as to give the impression that death had been due to a "crop-bound" condition of the chickens. Some have also supposed that these deaths were due to a mechanical injury of the crop by the spines on the legs of the insects having punctured the lining of this part of the digestive system while others have accounted for the death of these chickens by the rose chafers having bitten the crops.

A number of cases, some of which resulted in the loss of several hundred chickens, were reported to the writer and experiments in feeding rose chafers to chickens were taken up at the Storrs Agricultural Experiment Station in 1909.

The deaths from this diet usually occurred in from nine to twentyfour hours after feeding. This led the writer to believe that undoubtedly death resulted from a cause other than a mechanical injury to the crop or "crop-bound" condition. An extract was made from crushed rose chafers and distilled water, filtered, and fed to chickens in varying doses with a medicine dropper and this resulted in a great many deaths. Small chickens died in a few hours after feeding, older chickens of heavier weight, when fed a small quantity of the extract, lived but showed signs of poisoning; large doses resulted in their deaths. Mature hens did not die from the poison.

From 150 to 200 chickens have been fed either with the rose chafers 
or with varying strengths of the extract to determine the weight of the chicken killed by a certain amount of poison, also to determine the age limit of the chickens killed.

The results may be summarized as follows: 15 to 20 rose chafers are sufficient to cause the death of a chicken a week old. From 25 to 45 rose chafers are usually necessary to kill a three-weeks-old chicken. While some nine-weeks-old chickens have been killed by eating rose chafers, only one ten-weeks-old chicken was killed in these experiments. In the crop of this chicken there were 96 undigested rose chafers counted in post mortem examination.

The chickens feed upon the insects ravenously, being attracted by their sprawly appearance and usually within an hour after eating they begin to assume a dosing attitude, later leg weakness shows and the chicken usually dies within 24 hours of having eaten upon these insects, or begins to improve after this time.

In less than five per cent. of the deaths convulsions occurred. Post mortem examinations showed no abnormal condition of the organs. In order to exclude the possibility of arsenical poisoning duc to the rose chafers having probably fed upon leaves that had been sprayed, tests were made by a chemist for arsenic, but no evidence of arsenic was found. Intravenous injections also were made in these experiments, extracts for injection being made from forty grams of rose chafer and sixty grams (cc.) of a salt solution having a specific gravity of .9 per cent. This extract was put in a centrifuge for five minutes, the extract drawn off in a pipette and filtered in vacuo.

Three cc. of this extract was injected into a 690 gram rabbit intravenously and this died in six minutes. Another rabbit, weighing 1,435 grams, died after an injection of four cc. of this extract in three and one-quarter minutes. A small 610 gram rabbit, when injected with two and one-half cc., died in fifty-five seconds after injection, and a large 1,450 gram rabbit died in two hours and thirty-five minutes after being injected with two cc. Other rabbits were injected and killed by this extract but further work needs to be done to determine what is a lethal dose for rabbits and also experiments in feeding rabbits per os will be taken up next summer.

As near as the writer can determine, the rose chafers contain a neuro toxin, that has a direct effect upon the heart action of both chickens and rabbits and is excessively dangerous as a food for chickens.

Owing to the fact that the insect feeds upon such a large number of plants it seems essential that chickens be kept in mowed fields and away from yards having grape vines and any flowering shrubs during the month when rose chafers are most numerous, especially during years when rose chafers are particularly abundant. 